\title{
Biofuel's carbon balance: doubts, certainties and implications
}

\author{
John M. DeCicco
}

Received: 26 December 2012 / Accepted: 2 September 2013 / Published online: 21 September 2013

(C) The Author(s) 2013. This article is published with open access at Springerlink.com

\begin{abstract}
Liquid fuels will remain valued energy carriers well into any upcoming period when $\mathrm{CO}_{2}$ reductions are sought. Biofuels are the presumed replacement for the petroleum-based transportation fuels that dominate liquid fuel use. Lifecycle analysis embeds a closed-loop model of biofuel-related carbon flows, making net $\mathrm{CO}_{2}$ uptake an assumption to be refuted. However, evaluating net $\mathrm{CO}_{2}$ uptake through dynamic industrial and agriforestry supply chains at real-world commercial scales is extremely difficult. All such estimates carry a great deal of doubt and cannot be verified empirically. A different perspective follows by anchoring analysis in the certainty that end-use $\mathrm{CO}_{2}$ emissions from biofuels are essentially the same as those of the petroleum fuels they replace. A first-order model of the globally coupled bio- and fossil-fuel system reveals conditions for biofuel use to provide an atmospheric benefit. No benefit occurs in the energy sectors where biofuels are used, but rather must be found elsewhere in locations of carbon absorption or retention. The implication is that climate mitigation efforts should focus on such locations and include any mechanisms through which net uptake (an enhanced sink or verifiable offset) can be achieved by biological, chemical, geological or other means. Although biofuels can play a mitigation role when certain conditions are met, deemphasizing biofuel production in favor of terrestrial carbon management may offer more immediate and effective ways to counterbalance the $\mathrm{CO}_{2}$ emitted when using carbon-based liquid fuels of any origin. Climate policies for transportation fuels should be reconsidered accordingly.
\end{abstract}

\section{Introduction}

Biofuels, referring here to liquid fuels derived from biomass, are an important climate policy topic for several reasons. Like bioenergy in general, biofuels are a way to utilize the biosphere for energy production in a climate-constrained world (IPCC 2011). They can replace fuels derived from oil, which is the world's largest source of commercial energy (IEA 2012). Many policymakers view biofuels as necessary for addressing the large portion of transportation demand likely to require liquid energy carriers for the foreseeable future, particularly as automobile, truck and aircraft use rise in developing economies (IEA 2009, 2011). Nevertheless, biofuels are controversial because of the uncertainties that surround their net

J. M. DeCicco $(\bowtie)$

Energy Institute, University of Michigan, Ann Arbor,

MI, USA

e-mail: DeCicco@umich.edu 
climatic benefits; the conditions that need to be met for beneficial biofuel systems; and differences in methods, data and assumptions used for evaluation.

Broadly speaking, two approaches have been used to examine the greenhouse gas (GHG) impacts of biofuels. As commonly used for energy policy, lifecycle analysis (LCA) calculates trajectories of GHG fluxes for specified bioenergy product systems in comparison to reference fossil-based systems (Schlamadinger et al 1997; Cherubini et al 2009). LCA methods specifically designed for analyzing fuels compute a carbon intensity metric (lifecycle GHG emissions per unit of energy) for "fuels" as defined by feedstock and fuel product pathways involving particular production technology, land-use and spatio-temporal boundary assumptions (DeLuchi 1991; Wang 2004; Larson 2006; IPCC 2011 Section 2.5). Consequential versions of the LCA approach have been adopted for regulations such as the US Renewable Fuel Standard (RFS; EPA 2010), the California Low-Carbon Fuel Standard (LCFS; CARB 2010) and provisions of the European Renewable Energy Directive (RED; EU 2009).

The other approach is integrated assessment modeling (IAM), which offers comprehensive guidance regarding the climate impacts of biofuels but does so at a highly aggregate level. Such models examine bioenergy within a broader climate mitigation context that incorporates globally coupled climatic, biogeochemical and economic systems (e.g., van Vuuren et al 2009 and 2010; Wise et al 2009; Melillo et al 2009; and as further reviewed in Section 2.5.3 of IPCC 2011). IAM studies identify an important but conditional role for bioenergy (including biofuels) in climate mitigation, generally pointing to significant benefits only for advanced pathways (e.g., cellulosic rather than food crop feedstocks) with high yields, attention to resource constraints and land management, including carbon stock protection. IAM also suggests that biofuels offer benefits mainly during the latter half of the 21 st century when technology, land-use and other sustainability considerations are taken into account.

Although the most thorough LCA results are broadly consistent with many IAM findings, the dependence of LCA on system boundary assumptions (among other sources of uncertainty) results in a very divergent literature. Ideally, carefully qualified results from IAM would be used to guide public policy. What has happened instead is that policymakers have embraced certain LCA results, relying on simplistic, or at best inadequately qualified, interpretations of the fact that biofuels "recycle" carbon, i.e., that end-use $\mathrm{CO}_{2}$ emissions from combustion are fully balanced by $\mathrm{CO}_{2}$ uptake in feedstock growth. This closed-loop model of carbon flows is easy to understand and its intuitive appeal fosters a widespread popular belief that biofuels are inherently carbon neutral. Thus, policies have been designed under the assumption that carbon accounting need only address production-related, fossil-derived $\mathrm{CO}_{2}$ and other GHGs while excluding biogenic $\mathrm{CO}_{2}$ emissions throughout the fuel cycle.

To bridge the gap between biofuel-related policies rationalized by incomplete interpretations of LCA versus the guidance implied by IAM and more sophisticated LCA studies, it would be useful to have a conceptual framework that is transparent and well grounded in science but also accessible for policymakers. Such an approach can indicate policy directions consistent with fostering the conditions that comprehensive analyses imply are necessary for climate protection. To develop such a framework, this paper (a) takes a global view, to avoid the system boundary problems inherent to LCA; (b) anchors accounting in the "here and now," focusing on stepwise changes in $\mathrm{CO}_{2}$ sources and sinks while avoiding assumptions about the future (such as payback of carbon debt); and (c) avoids invoking the closed-loop model of biofuel-related carbon flows that results in a difficult verification problem regarding net $\mathrm{CO}_{2}$ uptake.

As a starting point, the discussion reviews the accounting issues that arise when specifying policy through LCA. It then deconstructs the biofuel lifecycle and then reconstructs its key elements using a simplified model of the globally coupled bio- and fossil-fuel system. The resulting framework offers insights about the conditions under which biofuels have a climate 
benefit and thereby where policy can best focus. No attempt is made to construct scenarios of particular biofuel pathways, exercises that are amply available in the literature. Rather, the discussion applies the simplified model to suggest policy directions consistent with the need for terrestrial carbon management as a precondition for bioenergy to contribute to mitigation; it also highlights the role of other options for counterbalancing the $\mathrm{CO}_{2}$ emitted from liquid fuel use.

\section{Accounting issues}

Figure 1 shows a simplified diagram of the lifecycles for a fossil fuel product such as petroleum gasoline compared to that of a biofuel such as ethanol. Traditional, or attributional, LCA methods of accounting address all GHG flows within the supply chain from feedstock production to fuel use. The effective system boundaries for the fossil fuel and biofuel are shown as the red (solid) line. LCA methods traditionally exclude indirect effects, enclosed by a brown (dotted) line. The fossil system boundary includes the entire supply chain plus vehicle emissions. For today's fossil fuels, vehicle end-use emissions dominate; for example, typical values for gasoline are $72 \mathrm{gCO}_{2} / \mathrm{MJ}$ at the tailpipe and $20 \mathrm{gCO}_{2} \mathrm{e} / \mathrm{MJ}$ during fuel production (GREET 2011).

For biofuels, because biogenic carbon is automatically credited within a product lifecycle, the boundary effectively excludes vehicle end-use $\mathrm{CO}_{2}$ emissions. Gaps also occur for biogenic $\mathrm{CO}_{2}$ released during biofuel production, e.g., from biomass combustion for process heat, fermentation or other conversion processes. The initial gap in the system boundary is for the $\mathrm{CO}_{2}$ absorbed in the feedstock, which is fully credited against biogenic $\mathrm{CO}_{2}$ releases throughout the supply chain and at end use.

\section{a PETROLEUM FUEL}
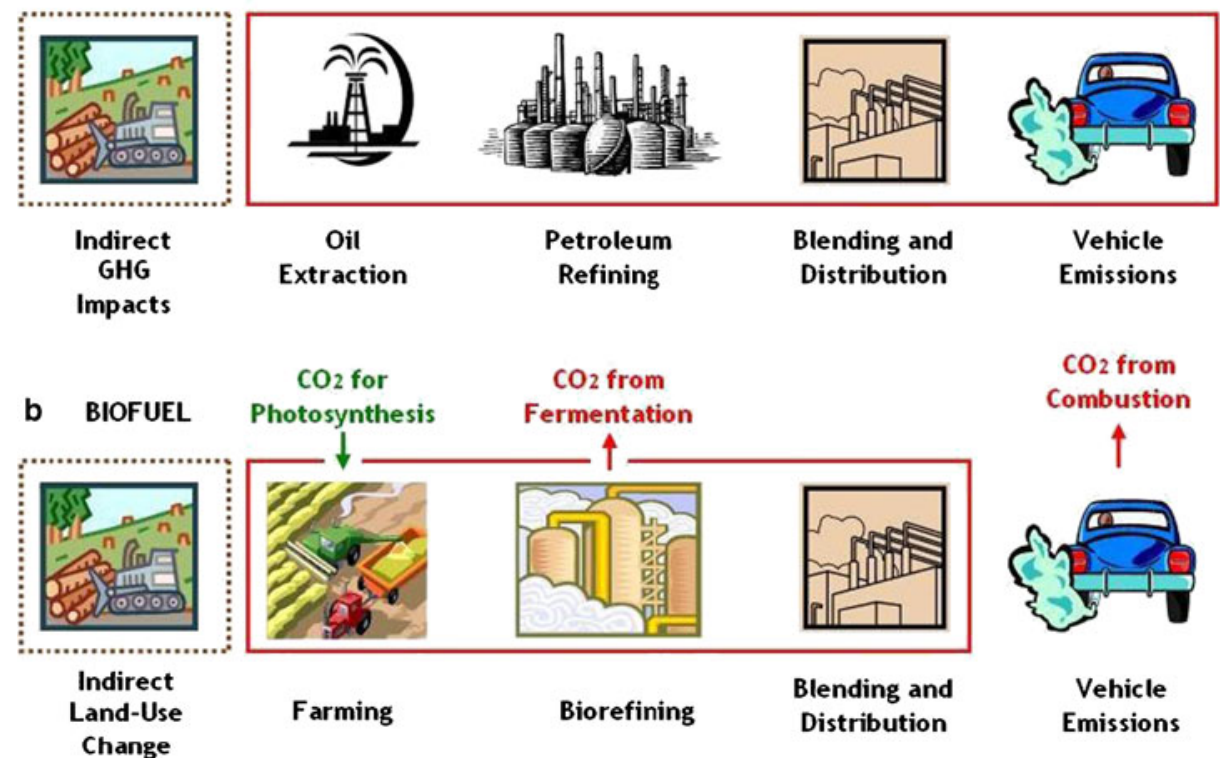

$\mathrm{CO}_{2}$ from

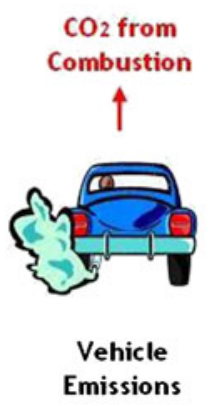

Fig. 1 System boundaries schematic for liquid fuel carbon balance. This simplified diagram highlights key aspects of carbon balance for fuel supply and use systems. A full depiction of GHG emissions would include many other details including soil carbon, $\mathrm{N}_{2} \mathrm{O}$ emissions, co-products and other impacts of both bio- and fossil-based fuel production 
Biogenic $\mathrm{CO}_{2}$ emissions are also omitted from energy sector GHG inventories under IPCC accounting guidelines, which address bioenergy by tallying carbon stock changes in land use and forestry sectors. In practice, however, carbon constraints have been imposed or proposed only in certain regions while carbon is unregulated in other regions where major land use change is occurring. The fact that such approaches treat biofuels as effectively carbon neutral by excluding direct $\mathrm{CO}_{2}$ emissions regardless of the carbon stock impacts of feedstock production has been flagged as an accounting error (Searchinger et al 2009).

\subsection{Limitations of closed loop accounting}

The problem with any accounting convention that effectively omits biogenic $\mathrm{CO}_{2}$ emissions is that the extent of net $\mathrm{CO}_{2}$ uptake in the biosphere is highly uncertain. Biofuels involve complex, dispersed and dynamic supply chains linking feedstocks and land use to fuel products. Although land-use change is not the only uncertainty, its magnitude can be large enough to negate near-term benefits from biofuels that compete for land, undermining confidence in LCAbased policies (Plevin et al 2010). NRC (2011) concluded that the RFS may be ineffective for reducing GHG emissions because of large uncertainties including those surrounding land use. Another recent study suggests that the RFS could result in increased GHG emissions (Mosnier et al 2013). Many analyses suggest that cellulosic technologies will yield more beneficial biofuels (Tilman et al 2009; Fairley 2011). Their projected indirect land-use change (ILUC) impacts are smaller than those of current biofuels; nevertheless, it is not possible to ascertain how such systems will develop at scale. Biofuels from bioengineered organisms or lowproductivity lands are being researched but remain speculative. In light of the risks, Gawel and Ludwig (2011) among others conclude that biofuel production should be limited to feedstocks with low risk to land, such as wastes.

A great deal of doubt therefore surrounds LCA estimates of biofuels' GHG impacts (Cherubini et al 2009; Delucchi 2010). A key question is whether the $\mathrm{CO}_{2}$ reduction claimed when substituting a biofuel for a fossil-derived fuel is additional in a carbon accounting sense (Searchinger 2010). The LCA methods used to justify policies that promote biofuels for climate mitigation build in an assumption that $\mathrm{CO}_{2}$ uptake in feedstock is fully additional. The result is a misplaced burden of proof because, by construction, LCA sets aside a certainty, namely, that the direct $\mathrm{CO}_{2}$ emissions from biofuels essentially equal those of the fossil-derived fuels they replace, and then incurs a large uncertainty about the extent to which net uptake or avoidance of $\mathrm{CO}_{2}$ emissions is achieved (DeCicco 2012). Attempting to address this uncertainty requires consequential analysis that then leads to compounding uncertainties and a need to make assumptions about time horizons, market behaviors, biomass yields and sequestration in the future. Therefore, biofuel LCA results not only are highly uncertain but also are scientifically indeterminate in the sense that they cannot be validated empirically, i.e., they are impossible to test against present-period or historical data. Indeed, comparing fuels using a LCA-based carbon intensity metric disregards the International Standards Organization guidance that "there is no scientific basis for reducing LCA results to a single overall score or number, since weighting requires value choices" (ISO 2006, p. 9).

\subsection{Direct Accounting}

Faced with this indeterminacy, it is prudent to set aside LCA and its closed-loop model of carbon flows. Analysis can be anchored in the certainty that end-use $\mathrm{CO}_{2}$ emissions rates vary little, falling within a range of $73( \pm 2) \mathrm{gCO}_{2} / \mathrm{MJ}$ for common liquid fuels (GREET 2011). The $\mathrm{CO}_{2}$ emissions from ethanol are just two percent lower than those from gasoline; biodiesel 
yields $\mathrm{CO}_{2}$ emissions about one percent greater than those from petroleum diesel; and drop-in biofuels have $\mathrm{CO}_{2}$ emissions identical to those of their fossil counterparts. Therefore, beyond actions to reduce liquid fuel consumption through lower travel demand, higher vehicle efficiency and shifts to electricity or hydrogen, fuel end-use is not where $\mathrm{CO}_{2}$ reductions can be found.

Moving up the supply chain, all current and near-commercial processes for synthesizing biofuels release more $\mathrm{CO}_{2}$ than petroleum refining regardless of whether fossil fuels or biomass wastes are used for process energy. LCA treats biogenic process $\mathrm{CO}_{2}$ as fully offset by the $\mathrm{CO}_{2}$ taken up during feedstock growth; however, these emissions enter the atmosphere just as do those from other industrial sources. In short, fuel processing is not a location of additional $\mathrm{CO}_{2}$ uptake.

Where $\mathrm{CO}_{2}$ uptake does occur is during biomass feedstock growth on productive land. At commercial scales, such production involves commodity market effects. As for crude oil and petroleum products, the physical liquidity that makes liquid fuels well suited for transportation also makes them inexpensive to transport, fostering trade that seeks least-cost locations of production. Because biomass growth is land intensive and conversion processes are inefficient compared to those for fossil fuels, market effects are globally significant even for small contributions to fuel supply. For example, corn ethanol production of 14 billion gallons (1.1 EJ) supplied $4.4 \%$ of total US transportation liquid fuel use of $26 \mathrm{EJ}$ in $2011 .{ }^{1}$ However, even that small share of liquid fuel supply required $45 \%$ of the US corn crop. ${ }^{2}$ Using a global trade model, a cumulative estimate of $800 \mathrm{gCO}_{2} / \mathrm{MJ}$ was obtained for the ILUC impacts of US corn ethanol production (Hertel et al 2010); a similar value is used in the CARB (2010) and EPA (2010) regulations. Parametric analysis suggests that larger values are more likely than smaller values around this nominal estimate (Plevin et al 2010). Although it represents non-recurring releases and foregone sequestration tied to expansion of production, this ILUC appears to be as much as an order-of-magnitude larger than end-use $\mathrm{CO}_{2}$ emissions from fuel use.

\section{Carbon balance analysis}

If additional net $\mathrm{CO}_{2}$ uptake occurs as a result of biofuel use, the location of that net uptake is land. Because commodity markets are involved, properly treating land use means that no system boundary short of the entire world will suffice. Once LCA is set aside in favor of direct carbon accounting that examines $\mathrm{CO}_{2}$ sources and sinks separately, better clarity emerges about options for addressing $\mathrm{CO}_{2}$ emissions from liquid fuel use.

\section{$3.1 \mathrm{CO}_{2}$ control options}

Table 1 lays out a hierarchy of options for mitigating $\mathrm{CO}_{2}$ emitted in the transportation sector. The options are described for motor vehicles but similar logic applies to other sources (such as aircraft or ships) that consume liquid fuels. The first tier in the table gives the standard factorization of emissions as a product of travel demand (vehicle miles of travel, VMT), average vehicle energy intensity and the GHG impact of supplying and using the fuel (DeCicco 2013). The first two factors determine the level of fuel demand. Beyond actions to reduce fuel demand,

\footnotetext{
${ }^{1}$ Derived from EIA (2012) and adjusted to a lower heating value (LHV) basis of comparison.

${ }^{2}$ From USDA (2012), which tallies gross corn demand as input to ethanol production facilities. Some analysts note that this value does not reflect any allocation to distillers' grains coproducts; assuming that coproducts account for about one-third of output, the fuel product might be seen as responsible for $30 \%$ of the corn crop.
} 
Table 1 Hierarchy of generalized $\mathrm{CO}_{2}$ mitigation options for transportation

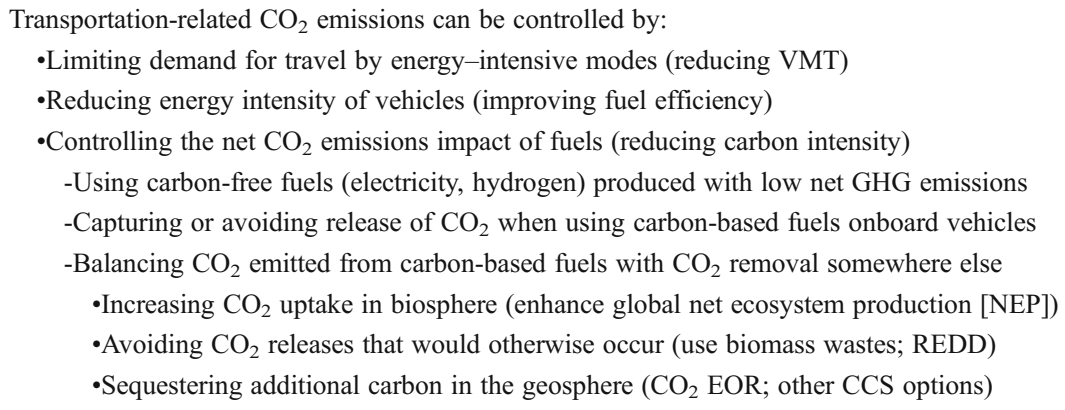

$V M T$ vehicle miles of travel, $G H G$ greenhouse gas, REED Reducing Emissions from Deforestation and Forest Degradation, EOR enhanced oil recovery, $C C S$ carbon capture and storage

$\mathrm{CO}_{2}$ reductions must be found through mitigation in the fuel supply system, a task commonly seen as shifting from petroleum fuels to alternatives such as biofuels, electricity or hydrogen.

The second tier in the table parses fuel-related mitigation into three categories. The first is to avoid direct release of $\mathrm{CO}_{2}$ from vehicles by using physically carbon-free energy carriers such as electricity or hydrogen, thereby shifting the mitigation task from the transportation sector to energy supply sectors. The second category (capturing $\mathrm{CO}_{2}$ onboard vehicles or utilizing the fuel without $\mathrm{CO}_{2}$ formation) is not practical with any known technology. The third category involves counterbalancing $\mathrm{CO}_{2}$ emissions from the use of carbon-based fuels with $\mathrm{CO}_{2}$ uptake in other locations. It can be further broken down into the three subcategories in the third tier of the table. Two involve the biosphere, either by increasing $\mathrm{CO}_{2}$ uptake in biomass which, as elaborated below, requires raising net ecosystem production (NEP), or by avoiding $\mathrm{CO}_{2}$ releases that otherwise would occur, e.g., by utilizing wastes as a feedstock. The final subcategory involves increasing sequestration in the geosphere.

\subsection{A first-order model}

Biofuels fall under the category of measures that seek to remove $\mathrm{CO}_{2}$ in one location in order to balance the $\mathrm{CO}_{2}$ emitted in other locations where fuels are burned. For analyzing this option it is helpful to define a simple model of globally coupled bio- and fossil-fuel interactions. The analysis examines an increment of biofuel use in the world as it exists today rather than trying to identify an ideal system for the future, and so considers stepwise changes in carbon balance instead of integrating across a future time horizon.

The analytic framework is illustrated in Figure 2, which shows carbon flows to and from the atmosphere with terrestrial and geological sources and sinks. The energy system engages all three pools and represents the technologies through which energy services (such as mobility) are delivered using carbon-based liquid fuels. To focus on core terrestrial carbon balance issues, oceans are omitted as are non- $\mathrm{CO}_{2}$ gases and emissions from energy processing (feedstock production, refining and biorefining). This sketch model enables a transparent analysis that replaces the LCA framework with a carbon cycle framework that emphasizes the separate locations of sources and sinks while examining current period changes in carbon flows.

Consider a change from an initial condition without biofuel use $\left(\mathrm{B}_{0}=0\right)$ to a condition with biofuel use $\left(\mathrm{B}_{1}>0\right)$. Examining here only the last tier of Table 1, liquid fuel consumption is fixed and so emissions from the energy system are unchanged $\left(\mathrm{E}_{1}=\mathrm{E}_{\mathrm{o}}\right)$. The carbon in extracted fossil 


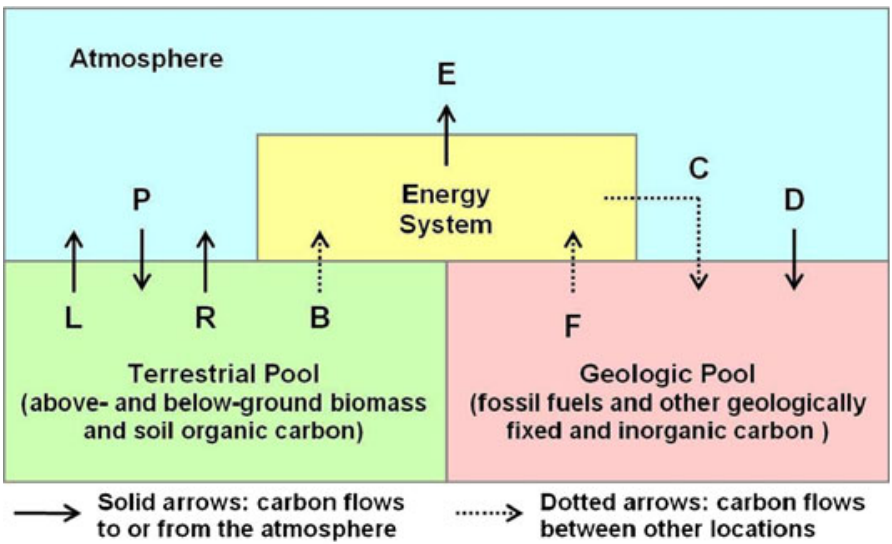

B Biofuel carbon

C Carbon captured from energy system

D Direct carbon capture from the atmosphere

E Carbon emissions from energy use

F Fossil fuel carbon

L Land-use change

P Net primary production

R Heterotrophic respiration

Fig. 2 Simplified carbon balance diagram for the globally coupled fossil and biofuel system associated with the use of carbon-based liquid fuels

fuel (F) is represented separately from the emissions (E) that result from fuel end use. For this analysis neither industrial carbon capture nor industrial direct air capture are considered $(\mathrm{C}=0$; $\mathrm{D}=0)$. Then, without biofuels, energy-related emissions equal the fossil carbon flow $\left(\mathrm{E}_{0}=\mathrm{F}_{0}\right)$.

In the initial condition, $\mathrm{P}_{0}$ represents terrestrial net primary production (NPP) on a global basis, which recently has averaged just above $50 \mathrm{PgC} /$ year. NPP was trending upward in earlier decades but evidence suggests a drought-induced decline over 2000-2009 (Zhao and Running 2010). Respiration (R) here refers to generalized heterotrophic respiration, i.e., $\mathrm{CO}_{2}$ from heterotrophs that directly or indirectly consume plants or other carbon-fixing autotrophs. $\mathrm{R}$ includes human uses of biomass, other than biofuel, that result in current period $\mathrm{CO}_{2}$ emissions, including food and feed but not conversion to durable products that keep carbon fixed. The net carbon entering the atmosphere is given by:

$$
\mathrm{A}=\mathrm{E}+\mathrm{L}+\mathrm{R}-\mathrm{P}-\mathrm{D}
$$

Note that the carbon in produced biomass (B) and fossil (F) feedstocks does not itself directly enter the atmosphere, but is mediated through the energy system to result in emissions (E) from the use of fuel products. Episodic $\mathrm{CO}_{2}$ releases from land-use change (L) are shown in Figure 2; however, assuming that a large $\mathrm{CO}_{2}$ release from the loss of terrestrial carbon stocks is to be avoided, $\mathrm{L}$ is treated as zero when deriving conditions for a beneficial increase in biofuel use.

With $\mathrm{L}=0$, positive global NEP represents the rate of biological carbon fixation, i.e., carbon moving on balance from the atmosphere to the terrestrial pool. Initial NEP is:

$$
\mathrm{N}_{0}=\mathrm{P}_{0}-\mathrm{R}_{0}
$$

Net carbon entering the atmosphere (A) is then:

$$
\mathrm{A}_{0}=\mathrm{E}_{0}-\mathrm{N}_{0}
$$

that is, the emissions from energy use less NEP. The sign convention here is that $\mathrm{P}$ and $\mathrm{N}$ are positive as sinks; $\mathrm{R}$ and $\mathrm{E}$ are positive as sources. 
Although $\mathrm{B}, \mathrm{E}$ and $\mathrm{F}$ can be quantified with reasonable certainty by tracking material flows, N, P and R are highly uncertain because their estimation requires complex modeling (e.g., Le Quéré et al 2009). Their global values cannot be measured directly and even sitespecific experimental estimates are difficult to obtain. Therefore, determining whether biofuels at real-world, commercial scales have a quantifiable climate benefit involves a severe test.

\subsection{Counterbalancing $\mathrm{CO}_{2}$ emissions from fuel use}

This simplified model enables a systematic look at the third tier of options outlined in Table 1, which involve counterbalancing the direct $\mathrm{CO}_{2}$ emissions from fuel end use.

\subsubsection{Increasing $\mathrm{CO}_{2}$ uptake}

The first subcategory of options involves increasing $\mathrm{CO}_{2}$ uptake in the biosphere. This case is represented by $\mathrm{P}_{1}>\mathrm{P}_{0}$ while leaving $\mathrm{R}$ unchanged. If the gain is devoted to biofuels, then $\mathrm{B}_{1}=\mathrm{P}_{1}-\mathrm{P}_{0}$ and $\mathrm{F}$ is reduced accordingly $\left(\mathrm{F}_{1}=\mathrm{F}_{0}-\mathrm{B}_{1}\right)$. Thus:

$$
\mathrm{N}_{1}=\mathrm{N}_{0}+\mathrm{B}_{1} \text { and } \mathrm{A}_{1}=\mathrm{A}_{0}-\mathrm{B}_{1}
$$

This effect can be seen as increasing NEP by increasing NPP, resulting in a decrease by $\mathrm{B}_{1}$ of the net flux to the atmosphere. Note that whether or not a biofuel is classified as first or second generation $^{3}$ does not change this basic assessment. In either case, the test is the extent to which NEP is increased during feedstock production. Even if a second-generation processing technology enables more biomass to be converted to fuel than is the case for a sugar, starch or oil crop, it is not the total production (NPP) that factors into improving the carbon balance (as commonly assumed in LCA). Rather, it is only the increase in NEP achieved by whatever management practices might be used to obtain a gain in $\mathrm{P}$ (or alternatively, as described next, a decrease in R).

Although this analysis omits process emissions from feedstock production and harvesting through biofuel refining and distribution, those impacts further raise the bar for biofuel's climate benefit. Consider a process:product carbon ratio of 1:1 (one ton of carbon emitted during processing for every ton of carbon in the finished product), a penalty much lower than that of most biofuel production processes. Each ton of energy-sector carbon displaced by biofuel then requires two tons of increased NPP because both process and end-use emissions must be offset by additional uptake. ${ }^{4}$ Raising NPP (e.g., increasing yields) often involves increasing agricultural inputs and therefore process emissions. In any case, increasing NPP in a manner that increases NEP is one mechanism through which biofuel production can have a carbon cycle benefit.

\subsubsection{Avoiding $\mathrm{CO}_{2}$ release}

A second way to counterbalance fuel end-use $\mathrm{CO}_{2}$ emissions is by avoiding the emission of $\mathrm{CO}_{2}$ from land where it otherwise would be released. In this case, NPP does not change

\footnotetext{
${ }^{3}$ First-generation biofuel technologies are those that exploit plants' own high-quality energy stores such as sugars, starches or oils. Second-generation technologies are designed to break down and use plants' structural materials, such as the cellulose and lignin that comprise the bulk of biomass and are available in wastes or residues.

${ }^{4}$ Fossil fuel products also have upstream emissions (e.g., a process carbon ratio of roughly 0.3 for petroleum gasoline) that would be avoided when substituting biofuels. Nevertheless, as long as fossil fuel refining is more efficient than biofuel production the point being made here does not change.
} 
$\left(\mathrm{P}_{1}=\mathrm{P}_{0}\right)$; carbon moves from the terrestrial pool to the energy system $\left(\mathrm{B}_{1}>0\right)$ and heterotrophic respiration is reduced accordingly $\left(\mathrm{R}_{1}=\mathrm{R}_{0}-\mathrm{B}_{1}\right)$. Fossil fuel is displaced $\left(\mathrm{F}_{1}=\mathrm{F}_{0}-\mathrm{B}_{1}\right)$ and so:

$$
\mathrm{N}_{1}=\mathrm{P}_{1}-\mathrm{R}_{1}=\mathrm{P}_{0}-\left(\mathrm{R}_{0}-\mathrm{B}_{1}\right)=\mathrm{N}_{0}+\mathrm{B}_{1}
$$

Again, NEP is effectively increased by the diversion of biomass to the energy system. The net flux into the atmosphere decreases accordingly:

$$
\mathrm{A}_{1}=\mathrm{E}_{1}-\mathrm{N}_{1}=\mathrm{E}_{0}-\left(\mathrm{N}_{0}+\mathrm{B}_{1}\right)=\mathrm{A}_{0}-\mathrm{B}_{1}
$$

This result corresponds to with the common perception of biomass wastes as an environmentally sound feedstock for biofuels. Biomass wastes or residues require second generation processing, which is starting to achieve some pilot-scale production (Wald 2012). The conversion of "marginal" land (not in agricultural production because it is economically marginal regardless of ecological value) to feedstock production can avoid $\mathrm{CO}_{2}$ release through removal of biomass that would otherwise break down. In practice, such land conversion for purposegrown biofuel feedstocks may involve both an increase in $\mathrm{P}$ and a reduction in $\mathrm{R}$, with the carbon cycle benefit still reducing to whatever gain is achieved in NEP.

\subsubsection{Benefit of additional fixed carbon}

This analysis shows that biofuels have a current-period climate benefit only if their feedstocks are derived from a higher rate of primary production $(\mathrm{P})$ or a lower rate of heterotrophic respiration $(\mathrm{R})$ than would otherwise occur. Either way, the effect amounts to increasing NEP as construed here, which means increasing the rate at which carbon is fixed in the biosphere. This reasoning is consistent with known principles for managing the terrestrial carbon stock, which entail either raising the rate of carbon input by increasing the rate of $\mathrm{CO}_{2}$ absorption from the atmosphere or lowering the rate of carbon loss by reducing respiration (Izaurralde et al 2013). When used for bioenergy, the additional biomass is diverted into the energy system and so does not accumulate in the biosphere. Although the gain in NEP does not increase the terrestrial sink, the effect is the same as far as atmospheric benefit is concerned.

Once additional carbon is fixed, sequestering it is just as effective as displacing fossil carbon for reducing $\mathrm{CO}_{2}$ buildup in the atmosphere (Marland and Marland 1992). For example, in the case of avoiding releases that would otherwise occur, $\mathrm{R}$ might be decreased through practices that increase carbon accumulation (letting forests regrow, rebuilding soil carbon, etc.). The gain in carbon stock then benefits the atmosphere as much as converting the added biomass into biofuels, and may be more effective if accomplished with lower GHG emissions for processing. In this case $\mathrm{R}_{1}<\mathrm{R}_{0}$, but without biomass diversion into the energy system. Fossil fuel use (F) is unchanged, but $\mathrm{N}_{1}>\mathrm{N}_{0}$ and so the net flux decreases. Similarly, because the atmosphere is indifferent to the location of sources and sinks, biofuel production can be evaluated against Reducing Emissions from Deforestation and Forest Degradation (REDD) and other programs for protecting terrestrial carbon stocks. Guidance can be taken from the longstanding research on how to manage land for carbon storage and directly address the associated land-use challenges (UNFCCC 2012). Mindful of the difficulties of verifying carbon flows, such programs are attentive to baselines, additionality, permanence, leakage and other concerns (Olander 2008), which is not the case for biofuel policies to date. 
Whether the additional carbon fixation is achieved by increasing P or decreasing $\mathrm{R}$ (or both), determining the best use of the fixed carbon then reduces to a question of economics. For example, making biofuel from wastes is but one way to avoid $\mathrm{CO}_{2}$ releases that would otherwise occur. ${ }^{5}$ Other options include managing the wastes to avoid decay, converting them to long-lived products or utilizing mainly the hydrogen for energy and sequestering the residual biochar. Biofuels do have value in the fuels market; nevertheless, carbon offsets may be more cost effective for mitigation, a likelihood highlighted by the way such offsets are viewed as cost containment measures for climate policy. In all cases, the starting point for comparing options needs to be in situ assessment of the change in NEP, which therefore requires knowledge of baseline NEP including any necessary adjustment for leakage. Options for the use of any additionally fixed carbon can then be evaluated by costs, market value, emissions and other environmental and social considerations.

\subsubsection{Geologic sequestration}

The third subcategory in Table 1 involves geologic mechanisms for offsetting the $\mathrm{CO}_{2}$ from liquid fuel use. Because CCS is not feasible onboard mobile sources, the "C" option shown in Figure 2 is not available for most forms of liquid fuel use. A " $D$ " pathway of direct air capture (DAC) of $\mathrm{CO}_{2}$ by chemical mechanisms or artificial photosynthesis is also technologically remote (APS 2011). Although DAC is unlikely to make sense until large stationary $\mathrm{CO}_{2}$ sources are nearly eliminated globally, it may be a very-long-term option for offsetting $\mathrm{CO}_{2}$ from dispersed sources such as transportation. For now, the biosphere offers more feasible ways to balance $\mathrm{CO}_{2}$ emissions from liquid fuel use than chemical removal with geologic storage.

That being said, petroleum firms are heavily involved in stationary CCS development, not least because it involves their core competencies in geology, chemical engineering and handling large volumes of liquids and gases. Carbon dioxide has been used for enhanced oil recovery (EOR) for many years. To date most $\mathrm{CO}_{2} \mathrm{EOR}$ has not involved sequestration; although efforts to expand this option are underway, the capacity of suitable EOR reservoirs currently appears small compared to the total $\mathrm{CO}_{2}$ emissions from liquid fuel use (NETL 2009). On the other hand, strategies for coordinating carbon sequestration with fossil hydrocarbon production have not seen a level of research on a par with that for traditional oil and gas extraction.

Other geologic options include coal-to-liquids (CTL) and coal+biomass-to-liquids (CBTL) with CCS (NRC 2009). Demonstration is also underway for CCS of $\mathrm{CO}_{2}$ from ethanol biorefineries, exploiting the relatively pure $\mathrm{CO}_{2}$ stream generated by fermentation (ADM 2009). Some studies suggest a long-run potential for negative emissions through bioenergy coupled with carbon capture and sequestration (Rhodes and Keith 2008; Azar et al 2010). In a multisector climate policy context, all such options are relevant to a coordinated program for limiting total GHG emissions from diverse sources including liquid fuels. Nevertheless, for sound implementation, any mechanism must be evaluated by the extent to which the biogenic carbon involved reflects an effective gain in NEP; such evaluation is not seen in the traditional LCA methods that underpin the literature to date (e.g., as reviewed by NRC 2009). A framework is required that prevents double-counting of reductions such as those avoided at stationary $\mathrm{CO}_{2}$

\footnotetext{
$\overline{5}$ Such waste management can have an added climate benefit of avoiding methane and nitrous oxide emissions. Nevertheless, once wastes find productive use they are no longer wastes; commerce will seek the least-cost sources and most profitable materials that policymakers classify as "waste." At scale, therefore, the use of biomass waste will still require evaluation of the effect on NEP rather than presumptively crediting the material as fully additional fixed carbon.
} 
sources and sequestered through $\mathrm{CO}_{2}$ EOR. Explicit, location-specific accounting of net impacts on sources and sinks is crucial for clarity.

\section{Discussion}

The foregoing analysis suggests a change in priorities regarding any near-term role for biofuels in climate mitigation. It has implications for all parties with an interest in fuels policy, including the petroleum and biofuel industries; automotive, trucking, airline and other transportation industries; researchers, technology developers and environmental advocates; and policymakers at all levels of government. Confidently guiding immediate action to mitigate climate change requires analysis anchored in the here and now of localized sources and sinks. At market-relevant scales, fuel product systems are complex, dynamic and expansive. The spatial boundary of a biofuel lifecycle extends globally and its temporal boundary extends into the future, rendering LCAbased GHG estimates scientifically indeterminate for reasons both practical and fundamental. The doubts only become greater when other climatic effects are considered (Delucchi 2010).

The prevailing wisdom has been that beneficial biofuels can be found if policymakers "sweat the details" in spite of an admitted "lack of consensus on how to measure environmental impacts of biofuels" (Fairley 2011: S4). Nevertheless, the "potential scales of biomass-based measures hinge on issues that are deeply, perhaps irreducibly uncertain ..." (Rhodes and Keith 2008: 326). Caution is also needed when interpreting studies that find a large potential for biofuels by identifying sufficient land for "sustainably" sourcing feedstocks but which rest on assumptions about ideal land management at vast scales.

\subsection{Short- vs. long-term considerations}

The approach given here works forward incrementally from present conditions instead of modeling hypothetical future systems. By construction, it precludes an accumulation of carbon debt because it identifies conditions under which an increase in biofuel use yields an immediate atmospheric benefit. The analysis contrasts with LCA methods that justify a large near-term release of carbon stocks due to land-use change by invoking assumptions about future system dynamics under which the resulting carbon debt gets repaid. Some may raise a concern that the near-term focus of this analysis creates a distorted (overly pessimistic) view of the mitigation potential of biofuels relative to continued fossil fuel use.

In fact, this analytic approach does allow for an increasing and potentially extensive use of biofuels for long-term climate mitigation. However, it constrains the rate of biofuel expansion to one that benefits the atmosphere a year at a time as determined by the availability of biomass that demonstrably reflects an increase in NEP. Thus, this framework can be viewed as offering policy guidance for achieving land use and feedstock sourcing conditions in line with mitigation scenarios involving biofuels (e.g., as reviewed in IPCC 2011). Such scenarios invoke assumptions regarding the availability of both land and technology for efficient conversion of cellulosic biomass produced under certain idealized land-use conditions. The present reality, however, is that of an expansion of biofuel use in the absence of commercially viable cellulosic conversion technology and, more importantly, in the absence of land-use governance that manages carbon at the scales impacted by biofuel feedstock demand. By underscoring the need to show that feedstock production measurably improves the terrestrial carbon balance, this analysis admittedly implies a cautious view of biofuels' mitigation potential. At the same time, it suggests policy principles consistent with realizing a long-term role for biofuels among the broader set of options for bio-based climate mitigation. 


\subsection{Carbon management considerations}

Biofuel proponents point out that productivity gains can minimize land-use impacts. However, productivity gains can also be directed toward more rapidly rebuilding terrestrial carbon stocks. Whether for supplying biofuel feedstocks or for recarbonizing the biosphere, evaluations need to be made according to region, biome type, land-use history and baseline conditions, non-carbon effects such as $\mathrm{N}_{2} \mathrm{O}$ emissions, other site-specific variables, and land and soil management practices (Lal et al 2012). Such an approach still faces the challenges of evaluating site and landscape carbon dynamics, including leakage. But by concentrating on specific locations where additional $\mathrm{CO}_{2}$ uptake is sought, it is possible to gain confidence by monitoring and making adjustments based on accumulating data. Circumscribed modeling of many effects will be needed, but location-specific characterization of carbon storage, GHG fluxes and other climatic effects is quite different than modeling fuel products at the terminus of a long, complex and dynamic chain of global impacts.

Localized carbon management can be thought of as following a key principle, genchi genbutsu, of the management approach developed by Toyota, commonly translated as "go to the spot" or "go and see for yourself" (Liker 2004). For the problem of mitigating $\mathrm{CO}_{2}$ emissions from liquid fuel use, the critical spots are the locations where it is hoped that net $\mathrm{CO}_{2}$ uptake is achieved and maintained. Without an empirical focus on such locations, neither biofuels nor any other form of mitigation based on $\mathrm{CO}_{2}$ uptake has a firm foundation on which to proceed. Once the quantity additionally fixed carbon is ascertained in a given circumstance, the next step is evaluating its best disposition based on economics and other societal considerations. Biofuels may have market value whereas other forms of disposition may not. However, in a climate mitigation context, fixed carbon is a good in and of itself (economists would say it should be "priced"). Re-releasing it by combustion in the form of biofuel (and during processing along the way) is not an obviously beneficial disposition and should be compared to other options for improving carbon balance. Developing policies that foster such evaluations for fuel-related markets is an important area of future work.

It is acknowledged that biofuels are promoted for reasons other than concern for climate; rural economics and energy security concerns have strong policy resonance. Only the climate rationale is treated here because, while running out of the atmosphere's ability to safely absorb $\mathrm{CO}_{2}$ is an immediate problem, running out of fossil hydrocarbons that can, at incremental cost, be refined into convenient liquid fuels is not (IEA 2012).

\section{Conclusion}

To date, many climate policy discussions have treated biofuels as a presumed if not indeed necessary strategy for mitigating $\mathrm{CO}_{2}$ emissions from liquid fuel use beyond the steps taken to limit fuel demand by improving efficiency and substituting non-carbon energy carriers. However, a great deal of doubt surrounds the LCA-based $\mathrm{CO}_{2}$ reductions claimed for biofuels. Such "carbon footprint" evaluations are unreliable for guiding near-term actions to mitigate GHG emissions.

Analysis can be anchored in a key certainty that LCA often obscures, namely, that the enduse $\mathrm{CO}_{2}$ emissions of similar liquid fuels are essentially the same. Carefully examining carbon sources and sinks reveals that no climate benefit is to be found in end-use sectors where liquid fuels might be substituted, but rather must be found elsewhere in sectors that supply feedstocks or other locations of $\mathrm{CO}_{2}$ uptake. A first-order model shows that biofuels are beneficial only to the extent that their production effectively enhances net ecosystem production. Given the global coupling of large-scale fuel and feedstock production and the atmosphere's indifference to 
locations of sources and sinks, the task is strictly one of achieving additional $\mathrm{CO}_{2}$ uptake. In short, the $\mathrm{CO}_{2}$ emitted when using carbon-based liquid fuels must be verifiably offset.

Broadly speaking, removing $\mathrm{CO}_{2}$ from the air through biological or other means requires carbon management. That in turn requires a "here and now" (in situ) attention to land use (terrestrial carbon management), geologic mechanisms or other options while measuring the quantity of carbon fixed and tracking it (including any released during processing) through its ultimate disposition. That could be as a feedstock for biofuels or other synthetic fuels, but also could be any forms of disposition including sequestration or long-lived products that keep carbon from reentering the air. Thus, the carbon mitigation challenge for liquid fuels has been incorrectly seen as a fuel synthesis and substitution problem. In reality, it is a net carbon uptake problem. Strategy should move away from a downstream focus on replacing fuel products to an upstream focus on achieving additional $\mathrm{CO}_{2}$ uptake through the most cost-effective and least damaging means possible. All parties with an interest in the issue are advised to rethink their priorities accordingly.

Acknowledgments The author is grateful to many colleagues for valuable discussions and to Bill Currie in particular for helpful insights about carbon cycle modeling, and also thanks both the anonymous reviewers and a number of collegial reviewers for comments on drafts. This work was supported in part through the US-China Clean Energy Research Center Clean Vehicle Consortium (CERC-CVC) under US Department of Energy Award No. DEPI0000012. The views and opinions expressed herein do not necessarily reflect those of the US government or any agency thereof, and the author retains sole responsibility for the content and conclusions.

Open Access This article is distributed under the terms of the Creative Commons Attribution License which permits any use, distribution, and reproduction in any medium, provided the original author(s) and the source are credited.

\section{References}

ADM (2009) A climate of innovation in Illinois: investigating geologic carbon sequestration's potential as an environmental solution. Fact Sheet. Decatur, IL: Archer Daniels Midland Co. http:/www.adm.com/enUS/responsibility/Documents/Carbon-Sequestration-Brochure.pdf

APS (2011) Direct air capture of $\mathrm{CO}_{2}$ with chemicals. Report. College Park, MD: American Physical Society. www.aps.org/policy/reports/assessments/upload/dac2011.pdf

Azar $\mathrm{C}$ et al (2010) The feasibility of low $\mathrm{CO}_{2}$ concentration targets and the role of bio-energy with carbon capture and storage (BECCS). Clim Chang 100(1):195-202

CARB (2010) Final regulation order: low carbon fuel standard. Sacramento, CA: California Air Resources Board; approved January 12. www.arb.ca.gov/regact/2009/1cfs09/finalfro.pdf

Cherubini F et al (2009) Energy- and greenhouse gas-based LCA of biofuel and bioenergy systems: key issues, ranges and recommendations. Resour Conserv Recycl 53(8):434-47

DeCicco JM (2012) Biofuels and carbon management. Clim Chang 111(3):627-640

DeCicco JM (2013) Factoring the car-climate challenge: insights and implications. Energy Policy 59:382392. doi:10.1016/j.enpol.2013.03.052

Delucchi MA (2010) Impacts of biofuels on climate change, water use and land use. Ann N Y Acad Sci 1195:28-45

DeLuchi MA (1991) Emissions of greenhouse gases from the use of transportation fuels and electricity. Report ANL/ ESD/TM-22. Argonne, IL: Argonne National Laboratory, Center for Transportation Research. November

EIA (2012) Annual energy review. US Department of Energy, Energy Information Administration, Washington, www.eia.gov/totalenergy/data/annual/index.cfm

EPA (2010) Regulation of fuels and fuel additives: changes to renewable fuel standard program; final rule. Washington, DC: US Environmental Protection Agency. Federal Register 75(58): 14669ff. March 26. www.epa.gov/otaq/fuels/renewablefuels/regulations.htm

EU (2009) Directive 2009/28/EC of the European Parliament and of the Council of 23 April 2009 on the promotion of the use of energy from renewable sources. Official Journal of the European Union 5.6.2009, L 140/16-62

Fairley P (2011) Next generation biofuels. Nature 474:S4-S5. doi:10.1038/474S02a, 23 June

Gawel E, Ludwig G (2011) The iLUC dilemma: how to deal with indirect land use changes when governing energy crops? Land Use Policy 28(4):846-856. doi:10.1016/j.landusepol.2011.03.003 
GREET (2011) The Greenhouse Gases, Regulated Emissions, and Energy Use in Transportation (GREET) Model. Argonne National Laboratory, Center for Transportation Research, Argonne, http:/greet.es.anl.gov/

Hertel TW et al (2010) Effects of US maize ethanol on global land use and greenhouse gas emissions: estimating market-mediated responses. Bioscience 60(3):223-231

IEA (2009) Transport, Energy and $\mathrm{CO}_{2}$ : Moving Toward Sustainability. International Energy Agency, Paris, www.iea.org/publications/free_new_Desc.asp?PUBS_ID=213

IEA (2011) Technology roadmap: biofuels for transport. International Energy Agency, Paris, www.iea.org/ publications/freepublications/publication/Biofuels Roadmap.pdf

IEA (2012) World Energy Outlook 2012. International Energy Agency, Paris, www.iea.org

IPCC (2011) Bioenergy. Chapter 2 (H. Chum et al.) In: O. Edenhofer, et al. (ed) IPCC special report on renewable energy sources and climate change mitigation. Intergovernmental Panel on Climate Change. Cambridge: Cambridge University Press

ISO (2006) Environmental management - Life cycle assessment - Principles and framework. ISO 14040:2006(E). International Standards Organization, Geneva

Izaurralde CR et al (2013) Managing carbon: ecological limits and constraints. Chapter 13. In: Brown DG et al (eds) Land use and the carbon cycle: advances in integrated science, management, and policy. Cambridge University Press, Cambridge

Lal R et al (eds) (2012) Recarbonization of the biosphere: ecosystems and the global carbon cycle. Springer, Heidelberg. doi:10.1007/978-94-007-4159-1

Larson ED (2006) A review of lifecycle analysis studies on liquid biofuel systems for the transport sector. Energy Sustain Develop X(2):109-126

Le Quéré C et al (2009) Trends in the sources and sinks of carbon dioxide. Nat Geosci 2:831-36. doi:10.1038/ngeo689

Liker JK (2004) The Toyota way: 14 management principles from the world's greatest manufacturer. McGraw-Hill, New York

Marland G, Marland S (1992) Should we store carbon in trees? Waste Air Soil Pollut 64:181-195

Melillo JM et al (2009) Indirect emissions from biofuels: how important? Science 326:1397-99

Mosnier A et al (2013) Alternative US biofuel mandates and global GHG emissions: the role of land use change, crop management and yield growth. Energy Policy 57:602-14. doi:10.1016/j.enpol.2013.02.035

NETL (2009) Storing $\mathrm{CO}_{2}$ and Producing Domestic Crude Oil with Next Generation $\mathrm{CO}_{2}$-EOR Technology. Report DOE/NETL-2009/1350. National Energy Technology Laboratory, January. Access via www.netl.doe.gov

NRC (2009) Liquid transportation fuels from coal and biomass. Report of the National Research Council. National Academies Press, Washington, http://www.nap.edu/catalog.php?record_id=12620

NRC (2011) Renewable fuel standard: potential economic and environmental effects of US biofuel policy. Report of the National Research Council. National Academy Press, Washington, www.nap.edu/catalog.php?record id=13105

Olander L (2008) Designing offsets policy for the United States. Duke University, Nicholas Institute for Environmental Policy Solutions, May, Durham, www.nicholas.duke.edu/institute/offsetspolicy.pdf

Plevin RJ et al (2010) Greenhouse gas emissions from biofuels' indirect land use change are uncertain but may be much greater than previously estimated. Env Sci \& Tech 44:8015-21

Rhodes JS, Keith DW (2008) Biomass with capture: negative emissions within social and environmental constraints: an editorial comment. Clim Chang 87:321-28

Schlamadinger B et al (1997) Towards a standard methodology for greenhouse gas balances of bioenergy systems in comparison with fossil energy systems. Biomass Bioenerg 13(6):359-375

Searchinger TD (2010) Biofuels and the need for additional carbon. Env Res Lett 5, doi:10.1088/1748-9326/5/2/024007

Searchinger T et al (2009) Fixing a critical climate accounting error. Science 326:527-28, October 23

Tilman D et al (2009) Beneficial biofuels: the food energy, and environment trilemma. Science 325:270-71, 17 July

UNFCCC (2012) Land Use, Land-Use Change and Forestry (LULUCF). Web pages. Bonn: United Nations Framework Convention on Climate Change. http://unfccc.int/methods and science/lulucf/items/1084.php

USDA (2012) Corn Background. Web pages. Washington, DC: US Department of Agriculture, Economic Research Service. www.ers.usda.gov/topics/crops/corn/background.aspx (Accessed 23 Nov 2012)

van Vuuren DP, van Vliet J, Stehfest E (2009) Future bio-energy potential under various natural constraints. Energy Policy 37:4220-30. doi:10.1016/j.enpol.2009.05.029

van Vuuren DP et al (2010) Exploring IMAGE model scenarios that keep greenhouse gas radiative forcing below $3 \mathrm{~W} / \mathrm{m}^{2}$ in 2100. Energy Econ 32(5):1105-1120. doi:10.1016/j.eneco.2010.03.001

Wald ML (2012) Fuel from waste, poised at a milestone. The New York Times, Nov. 14: B1

Wang MQ (2004) Fuel cycle analysis of conventional and alternative fuel vehicles. In: Cleveland CJ (ed) Encyclopedia of Energy 2. Elsevier, New York, pp 771-789

Wise M et al (2009) Implications of limiting CO2 concentrations for land use and energy. Science 324:1183-86, 29 May

Zhao M, Running SW (2010) Drought-induced reduction in global terrestrial net primary production from 2000 through 2009. Science 329:940-943. doi:10.1126/science.1192666 